\title{
Are there cities at risk of disappearing_an inconvenient truth?
}

\author{
Masaaki Hosomi
}

Published online: 11 February 2015

(c) Springer-Verlag Berlin Heidelberg 2015

Population is an inextricable problem in discussions on sustainability. Reportedly, the world population will peak at 10 billion and afterward start decreasing slowly. In Japan, however, population has raised different worries. There was a shocking news on this matter in newspapers and TV in May 2014. The Japan Policy Council (2014) reported that 869 municipalities out of 1800 in Japan are at risk of disappearance!

The population in Japan has increased by two and a half from early 1600-1700, reaching 30 million, according to Development Bank of Japan, 2014. In the eighteenth century, agricultural tax began to be levied based on land area measurement, which was an incentive to farmers to cultivate more. The implementation of this tax policy allowed farmers to be independent, resulting in development of new fields and yielding higher productivity. In 1721, population census was performed by the Shogunate Government of Edo. But the population did not change from the middle of 1700 for 150 years when this government held onto power. The constant population during this period was due to starvation, illness, natural disasters, and also restriction of economic development because of Japan's national isolation. Since Meiji Era, the population has increased by a factor of approximately 4, from 33 to 128 million (in 2008). The increase has been attributed to progress of industrialization, improvement of standard of living, and improving medical services, resulting in lower mortality rate. However, since 2010, the population has decreased by 200,000 people every year. In January 2015, the population in Japan is 127 million 20 thousand (Estimated value by

M. Hosomi ( $\square)$

Tokyo University of Agriculture and Technology, 2-24-16,

Nakamachi, Koganei, Tokyo 184-8588, Japan

e-mail: hosomi@cc.tuat.ac.jp
Statistics Japan, 2015) and the population over 65-year old occupies $25 \%$ of the total population. According to the investigation by National Institute of Population and Social Security Research, the total population in Japan is expected to be 86 million 740 thousand in 2060. As the population aging further proceeds, the population ratio over 65 years will occupy $39.9 \%$.

The statistics cited above indicate that the social security system in Japan will not be sustainable at all. The outstanding obligation of the government is currently 10 trillion US dollars. This money will not be easily found. This is mainly caused by a low birth rate; therefore, several actions for this matter were taken. For example, the minister of State for Measures for Declining Birthrate was appointed in 2007 and has been taking the initiative in continuing countermeasures for the low birth rate. Regarding a countermeasure for the low birth rate, the Basic Act on Measures for the Aging Society was enacted on 8th January 1995. The objectives of the basic act were to highlight and support a view of an ideal society, where citizens meaningfully and comfortably live require many more young members in the families to support senior citizens. Based on the basic act, the General Principles Concerning Measures for the Aging Society were concomitantly formulated (http://www8.cao.go.jp/kourei/mea sure/taikou/etaikou.htm\#p301).

Notwithstanding the Basic Act, twenty years later today the birth rate still has not improved and Japan is entering a society of population decline. Therefore, it is imperative for Japan to prevent such a situation. Masuda et al. (2014) announced cities at risk of disappearing in Japan to make the people accurately and soberly recognize, as a starting point, the emerging matter, the so-called "inconvenient truth". In other words, in the cities at risk child-bearing female population aged between 20 and 39, i.e., the female 
youth population, will decrease by more than $50 \%$ from 2010 to 2040. When the reproductive female youth population in a municipality decreases by more than $50 \%$, the total population would be difficult to maintain despite an increase in a birth rate, and so would long-term care and health insurances. In addition, assurance of employment would be difficult, making a municipality incapable of sustaining administrative functions. The municipalities listed as a city at risk of disappearing started expressing a sense of crises and considering a scheme of a society where female youths can take an active part. Above all, Toshima City, as the only city at risk of disappearing in Tokyo Metropolitan, immediately launched an emergency headquarter headed by the mayor and started a leading project for "town planning incentive for women". Moreover, the council called "Toshima F1" composed of women in the middle of child raising was commissioned to survey opinions and needs from female youths. The F1, which is a term used to designate women between age 20 and 34 generally used in advertising and broadcasting, reveals attitudes toward actions for future in Toshima City with a sense of speed like formula one. It is now clear to us that an indicator, "female youth population," would be an appropriate sustainability indicator to be used for regional sustainability determination and tracking. 